THOMAS J. BLOEM, DDS, MS, and

MICHAEL E. RAZZOOG, DDS, MS, MPH

\title{
An index for assessment of oral health in the edentulous population
}

T HROUGHOUT DENTAL literature, books and articles describe the prevalence of inflammation of supporting structures beneath complete dentures. The nature and cause of this problem have been widely studied, but the methods used to report inflammatory changes have been less than consistent. Quantification of inflammation via indexes should ascribe numerical values to the relative oral health of a population on a graduated scale. Such indexing would allow comparisons between patient populations using the same criteria, even though these groups may be separated by time and locale.

Agencies concerned with dental public health rely heavily on indexes of oral disease to target resources and to evaluate the effectiveness of programs. With ever-increasing emphasis on programs of capitation, geriatric dental access, community clinic care, and government-funded health centers, there is a need for effective screening of patients and assessment of treatment results for epidemiological purposes.

The geriatric population has a high incidence of edentulism. Physical health, drug therapy, nutritional intake, and personal hygiene have been reported to correlate with basal seat tissue health in these individuals. Inflammatory tissue changes in mouths of edentulous patients have been hypothesized to have a direct detrimental effect on denture-supporting mucosal health and underlying basal structures. Furthermore, the success or failure of prosthodontic treatment in terms of patient comfort and function is directly linked to tissue health.

If future research is to provide the basis for programs in the assessment and reduction of this disease process, a reliable, valid, economic, and simple method of evaluation must be accepted.

The subjective evaluation of the health of the basal seat area has been consistently applied in prosthodontics. Despite exacting clinical procedures to ensure healthy tissue, the visual appraisal of these tissues has not included distinct criteria for determining this health. ${ }^{1-4}$ Few methods of clinical description of tissues have allowed serial examination and objective categorization of findings. Dental literature provides mechanisms for tissue health assessment of the basal seat area that are timeconsuming and do not allow immediate clinical application. Methods such as electromicroscopy, ${ }^{5}$ microradiography, ${ }^{5,6}$ biopsy, ${ }^{7}$ histochemistry and histopathology, ${ }^{8}$ tissue culture, and exfoliative cytology are certainly valid, but confine the efforts to the laboratory setting.

The Prosthodontic Tissue Index was developed in a manner similar to periodontal indexes to provide simple, objective clinical evaluation of basal supporting tissues. ${ }^{912}$

At the University of Michigan School of Dentistry, patients edentulous in one or both arches were examined by a primary examiner (caliber) and a calibrated coexaminer. The examiners previously were calibrated by a standardized photographic description and written criteria for gradations in tissue health. In a study of gingival color, Lees said, "The ability to refer constantly to the baseline condition will protect examiners against all the current difficulties of applying criteria to conditions that, by their very nature, have no finite limits. In addition, examiners using photo-
GERIATRIC DENTISTRY

Quantification of inflammation via indexes should ascribe numerical values to the relative oral health of a population on a graduated scale.

Special Care in Dentistry

Vol. 2 No. 3 May-June 1982 
graphics will be constantly reminded of their examination standards and will be less likely to GERIATRIC depart from them."13 Therefore, color photoDENTISTRY graphs, when standardized, are conducive to reliability in tissue assessment and recorded information.

Training sessions were held with clinical patients until an interexaminer reliability of greater than $80 \%$ was obtained during several sessions. The inflammatory status of patients' basal seat tissue was charted on a grid for each arch, delineated by major areas of denture support. For this study, the maxillary arch was divided into four segments, which included the broad expanse of the hard palate; the residual ridge from hamular notch to canine fossa bilaterally (vestibule inclusive); and the anterior residual ridge including the labial vestibule (Fig 1).

The mandibular arch was divided into five areas of denture support: the retromolar pad

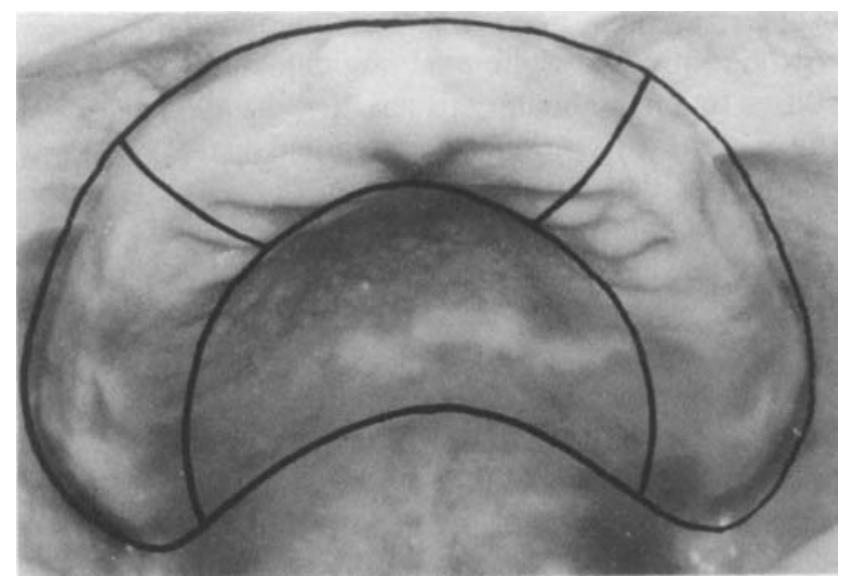

Fig 1. Maxillary arch, delineated by major areas of denture support.

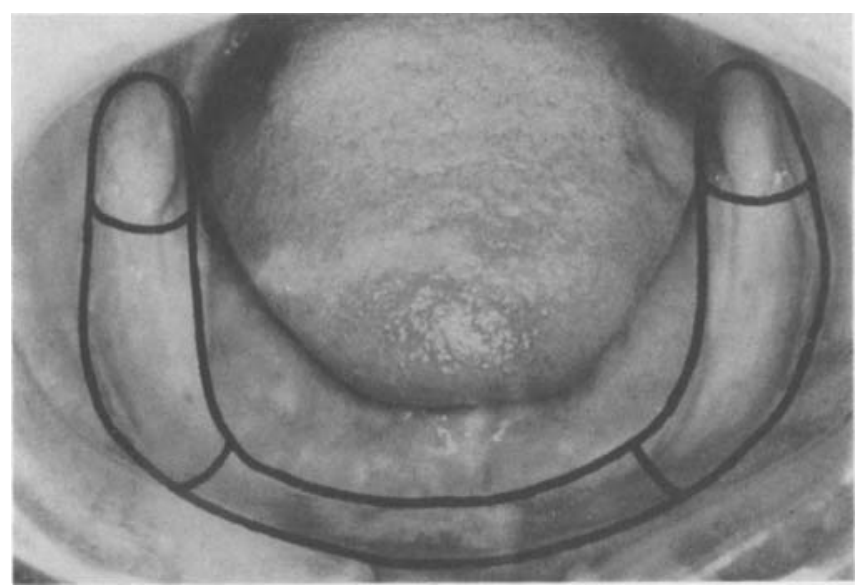

Fig 2. Mandibular arch delineated by major areas of denture support. bilaterally; the residual ridge from retromolar pad to canine region bilaterally (buccal and lingual vestibules, inclusive); and the anterior residual ridge, including labial and lingual vestibules (Fig 2).

In each segment of the edentulous arch, the patient's oral health status was scored based on changes in color. A normal, or 0 tissue surface was pink, had normal vascularity and a matte appearance (Fig 3). Areas with an inflammatory status of 1 were reddened or had solitary hyperemic foci. The surface generally had a matte appearance (Fig 4). A rating of 2 applied to areas reddened and with multiple hyperemic focci, the general appearance being glossy (Fig 5 ). When the tissue was distinctly red or redblue, with or without hyperemic foci, and glossy, the area was rated as a 3 (Fig 6). Additionally, the presence of any lesions or tissue abnormalities, or both, that might modify prosthodontic care were identified.

After the collection of data was completed, a parametric analysis, consisting of conventional tabulations and correlations, was made based on percentages. Assuming that inflammation existed to some degree when a tissue color value greater than 0 was assessed, the incidence of inflammation was tabulated for the study population. Of 141 patients edentulous in both the maxillary and mandibular arches, only four had normal tissue health in all areas, reflecting a $97 \%$ incidence of inflammation to some degree. Sixty percent of the patients had oral lesions or tissue abnormalities that would significantly modify prosthodontic care.

In addition to the charting of oral inflammation on the basis of color, the patients were asked a series of questions relating to prosthodontic history, problems with dentures, and oral hygiene habits. Patients' responses disclosed that the average time since the patient's last oral examination had been 6.1 years, while they had worn their existing prostheses an average of 8.7 years. The average length of time edentulous was 20.2 years, and the average patient had worn two different sets of dentures during that time. These figures reflect a disconcerting trend toward oral neglect in the edentulous population. Unless formally supervised, patients would appear to go to dental offices for the fabrication of prostheses with little recall or maintenance care intended. Furthermore, in all categories of inflammation, the patients could not relate personal oral comfort to the observed oral health status. Indeed, patients were nearly equally divided between statements of oral comfort and complaints of discomfort, even in 
Fig 3. Type 0 tissue color: pink, normal vascularity, matte appearance.
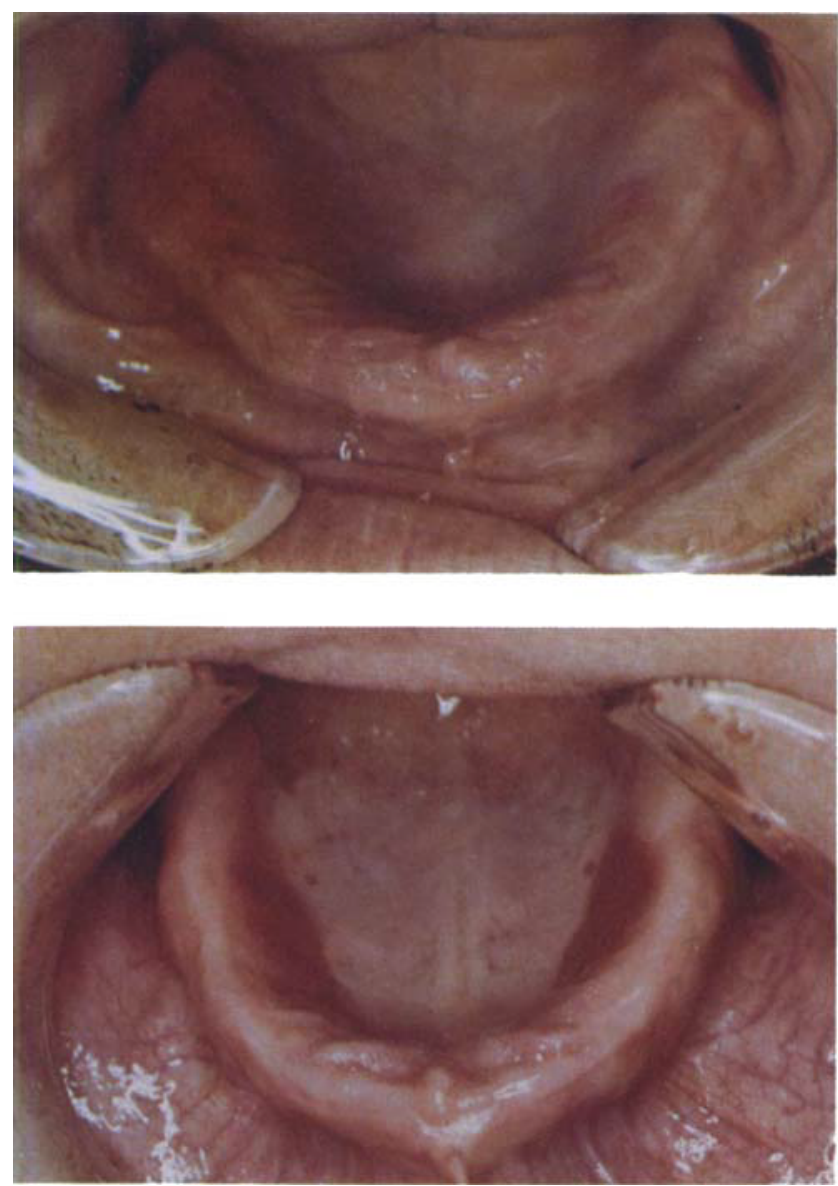

Fig 5. Type 2 tissue color: reddened multiple hyperemic foci, glossy appearance.

the worst cases of inflammation.

\section{CONCLUSION}

Dental health care must be concerned with the preservation of health and function in middle and older age groups. The principal epidemiological characteristics of the edentulous population studies were: that most patients with complete dentures have pathologic tissue changes that require treatment, and that tissue changes have little relation to a patient's perception of denture success or personal oral health status.

Ongoing research in the area of general physical health, nutrition, and oral hygiene is essential to enhance understanding of dental health needs in the edentulous elderly. The need for epidemiological data related to supporting structure inflammation and its effect on comfort and function will continue to increase owing to the aging demographics of the United States population.
Fig 4. Type I tissue color: reddened solitary hyperemic foci, matte appearance.
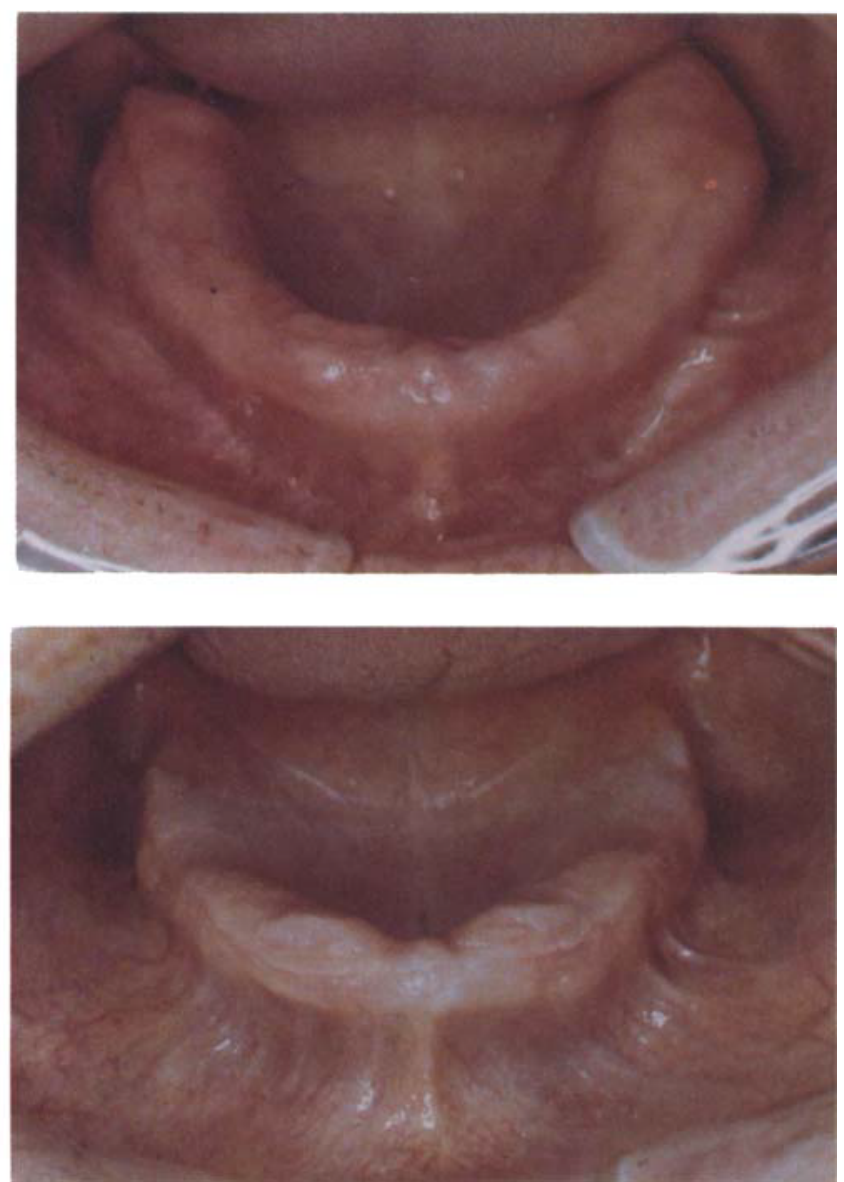

Fig 6. Type 3 tissue color: distinctly red or red-to-blue, with or without hyperemic foci, glossy appearance.

\section{SUMMARY}

Success or failure of prosthodontic treatment, in terms of comfort and function, is linked to tissue health. To date, no baseline indication of inflammatory status has been available to objectively evaluate preprosthetic tissue preparation. The Prosthodontic Tissue Index (PTI) was developed in a manner similar to periodontal indexes, to provide objective clinical evaluation of basal supporting tissues. At the University of Michigan, 150 patients who were edentulous in one or both arches were examined and asked a series of questions relating to their prosthetic history. The inflammatory status of basal seat tissues was scored according to defined observable inflammatory changes.

Inflammation status was charted on a grid delineated by major areas of denture support for each arch. In $97 \%$ of patients examined, inflammatory changes requiring some degree of preprosthetic management were found. Tissue
GERIATRIC DENTISTRY

Special Care in Dentistry

Vol. 2 No. 3

May-June 1982 
GERIATRIC DENTISTRY

abnormalities other than inflammation that required specific management were noted in $62 \%$ of the patients. Although nearly all patients registered problems relative to their prostheses, most were not aware of the extent of their tissue changes.

Dental care should be concerned with the preservation of health and function in the middle and older ages. Principal epidemiological characteristics of the edentulous population showed that: most patients with complete dentures have pathologic tissue changes that require treatment; and tissue changes have little relation to a patient's perception of denture success or personal oral health status.

Dr. Bloem is assistant professor, and Dr. Razzoog is associate professor, complete denture defartment, University of Michigan School of Dentistry, Ann Arbor, 48109. Requests for reprints should be sent to Dr. Bloem.

1. House, M.M. An outline for examination of mouth conditions. Dominion Dent J 33:97-100, 1921.
2. Lytle, R.B. The management of abused oral tissues in complete denture construction. J Prosthet Dent 7:27-42, 1957.

3. Klein, I.E., and Miglino, J.C. Uses and abuses of tissue treatment materials. J Prosthet Dent 16:1-4, 1966

4. Budtz-Jorgensen, E. Clinical aspects of Cundida infection in denture wearers. JADA $96(3): 474-479,1978$.

5. Wictorin, L., and others. Denture stomatitis: a clinical, EM, microradiographic and light microscopic study. Acta Odontol Scand 33(5):299-311, 1975.

6. Dukes, B.S. Soft tissue responses following removal of illfitting dentures. Ky Dent Assoc J 17:29-32, 1965.

7. Jani, R.M., and Bhargava, K. A histologic comparison of palatal mucosa before and after wearing complete dentures. J Prosthet Dent 36:254-260, 1976.

8. Razek, M.K., and Shaaban. N.A. Histochemical and histopathologic studies of alveolar mucosa under complete dentures. J Prosthet Dent 39:29-36, 1978.

9. Ramfjord, S.; Kerr, D., and Ash, M., eds. World workshop in periodontics. Ann Arbor, University of Michigan, 1966.

10. Cohen, D.W., and Ship, I.I. Clinical methods in periodontal diseases. J Periodontol 38:6, 1967.

11. Glickman, I. Indices for the epidemiologic study of gingival and periodontal disease. Clinical periodontology, ed 4. Philadelphia, W. B. Saunders, 1972.

12. Massler, M., and Schour, J. The P-M-A index of gingivitis, J Dent Res 28:634, 1949

13. Lees, G.H. Assessment of gingival change using color photography. Comm Dent Oral Epidemiol 2:225-230, 1974.

\section{Editor's Note}

This poem was given to the editor by a 93 -year-vital lady. It is sensitive, thoughtful, and perceptive and should dispel misconceptions about aging. Mrs. Longshore is an example of an individual with an enduring capacity to be thoughtful and eloquent. Sidney Epstein, DDS, Editor

Vol. 2 No. 3

\section{Ask and It Shall be Given You}

When I was very young,

I confused God with Santa Claus.

"Ask and it shall be given you,"

Said the text we learned in Sunday School.

And in my prayers $I$ asked for many things:

For a pony, and for curly hair, and money

And (later) for popularity.

And not one of these things was given to me.

Now, a lifetime later, I think

1 know a little more about God's giving.

God cannot and will not make the sun stand still,

Nor volcanoes stop erupting,

Nor our armies win in battle.
Nor stocks go up, nor the blind see, and the deaf hear,

Nor will he purge all evil by a miracle.

But He will give you, if you ask,

An understanding heart, courage, compassion, patience

And eyes to see the beauty $\mathrm{He}$ has made,

From blades of grass to ever-wheeling stars.

And love, above all He will give you love.

All these God gives, abundant as the dew.

Spirit of life,

and source of all divine within us-

This is God.

Edna C. Longshore 